\title{
A new class of organosilane-modified polycarboxylate superplasticizers with low sulfate sensitivity
}

Wei Fan ${ }^{\mathrm{a}}$, François Stoffelbach ${ }^{\mathrm{b}}$, Jutta Rieger ${ }^{\mathrm{b}}$, Laure Regnaud ${ }^{\mathrm{c}}$, Angélique Vichot ${ }^{\mathrm{c}}$, Bruno Bresson ${ }^{a}$ and Nicolas Lequeux ${ }^{\mathrm{d}^{*}}$

${ }^{a}$ Laboratoire de Physico-Chimie des Polymères et des Milieux disperses, UMR 7615, ESPCI, 10 rue Vauquelin 75231 Paris cedex 05, France

b Laboratoire de Chimie des polymères, UMR 7610, UPMC, 3 rue Galilée, 94200 Ivry sur Seine, France

${ }^{c}$ CTG Italcementi Group, Les Technodes - BP 01, 78931 Guerville, France

d Laboratoire de Physique et d'Etude des Matériaux, UMR 8213, ESPCI, 10 rue Vauquelin 75231 Paris cedex 05, France

* Corresponding author. Tel.: +33 (0)1 407944 41; fax: +33 (0)1 40794640

E-mail address: nicolas.lequeux@espci.fr 


\begin{abstract}
It is well-established that a competitive adsorption exists between polycarboxylate superplasticizers (SP) with soluble sulfate ions solubilized in interstitial solution of cement paste, which may causes a loss of dispersing properties depending on the cement composition. Early reports suggested that this incompatibility is due to competitive weak ionic interaction between functional acrylate groups and solubilized sulfate ions with cement grains. In this study, SPs including trialkoxysilane functional groups have been synthesized via radical copolymerization of methacrylic acid, poly(ethylene glycol) methyl ether methacrylate and trimethoxysilyl propyl methacrylate. Adsorption and dispersing properties of these new SPs were evaluated in cement paste at different concentration of $\mathrm{Na}_{2} \mathrm{SO}_{4}$ added in aqueous solution. Partial substitution of acrylate groups by trialkoxysilane in the polymer composition significantly enhances the compatibility with sulfate ions. We suggested that the high adsorption capacity of these SPs results from the formation of strong bonds between hydroxysilane groups and calcium silicate hydrate phases present at the surface of $\mathrm{C}_{3} \mathrm{~S}$. The improved compatibility of these new silylated SPs with cements more or less rich in sulfate alkaline has been demonstrated through the formulation of two different concrete equivalent mortars.
\end{abstract}

Keywords: Polymers D; Sulfate D; Adsorption C; Dispersion A; Workability A; Superplasticizer 


\section{Introduction}

Polycarboxylate-type superplasticizers (SP) with polyethylene glycol (PEG) side chain are very efficient in the formulation of high-performance concrete due to their excellent water reducing capacity.[1] The dispersing mechanism of these superplasticizers is generally thought to be related to the adsorption of polymer backbone via carboxylic functional groups and the steric hindrance effect generated by PEG side chains.[2-5] However, it is known that the dispersing performance of SPs is significantly affected by many parameters such as cement composition and mixing conditions.[6-8] This incompatibility makes it hard to control or to predict the concrete workability with these particular plasticizers. [9] Sulfate ions dissolved in the interstitial solution of cement paste seems to be one of the most important parameter having an adverse impact on SP adsorption.[10,11] Yamada et al. demonstrated that polycarboxylate polymer can desorb when the soluble sulfate concentration in the interstitial solution is raised by addition of $\mathrm{Na}_{2} \mathrm{SO}_{4}$, and then causes a loss in fluidity. Conversely, when the sulfate concentration is reduced by precipitation of gypsum using $\mathrm{CaCl}_{2}$, the fluidity is improved due to an increase of polymer adsorption. These observations suggest that a competition between $\mathrm{SO}_{4}{ }^{2-}$ and $\mathrm{COO}^{-}$adsorption occurs on cement surface.[12] The influence of SP structure on the sulfate-polycarboxylate competition has been studied by Zimmermann et al.[13] It was found that the sulfate sensitivity depends mainly on the polymer architecture. The sulfate sensitivity increases with the polyethylene glycol (PEG) side chain length and the PEG/carboxylate ratio.[14] In consequence, SP architecture are generally adapted to each type of cement, and the use of a designed SP for particular high alkali cement may cause problems when used with low alkali cements, such as variations of dispersing properties, rheological behavior, setting time, etc. So, there is an urgent need to improve the performance of SP to make these adjuvants more robust with respect to the composition of raw materials.

To circumvent the sulfate-carboxylate competition, one solution would be to include functional groups into the polymer backbone able to form sufficiently strong bonds to be unaffected by sulfate ions. In a previous work, we have found that a new layered calcium organosilicate hybrids can be formed with covalently linked organic functionalities [15], and silylated hydrosoluble polymers can be covalently bonded to calcium silicate hydrate (C-S-H) [16]. Organosilane functions incorporated into SPs would be benefit to limit the problem of sulfate-carboxylate compatibility. For this purpose, a series of polycarboxylates modified by insertion of trimethoxysilane functions have been synthesized and their adsorption and 
dispersing properties has been investigated as well as their adsorption resistance against sulfate ions.

\section{Experimental}

\subsection{Materials}

Methacrylic acid (MAA, purest grade, Acros, stabilized with $250 \mathrm{ppm}$ of methylethylhydroquinone), poly(ethylene glycol) methyl ether methacrylate (MAPEG, $\mathrm{M}_{\mathrm{n}}$ 1100 g.mol ${ }^{-1}$, Aldrich), 3-(trimethoxysilyl) propyl methacrylate (MAPTMS, 98\%, Acros), 4,4'-azobis(4-cyanovaleric acid) (ACPA, $\geq 98 \%$, Fluka), 1-butanethiol (BuSH, 99\%, Aldrich), tetrahydrofuran (THF, >99\%, Acros), diethyl ether $\left(\mathrm{Et}_{2} \mathrm{O}\right.$, pure, Acros), $\mathrm{Al}_{2}\left(\mathrm{SO}_{4}\right)_{3} \cdot 16 \mathrm{H} 2 \mathrm{O}$ (Fluka) and $\mathrm{CaCO}_{3}$ (Aldrich) were used as received without further purification.

2.2. Synthesis of poly(poly(ethylene glycol) methyl ether methacrylate-co-methacrylic acidco-3-(trimethoxylsilyl) proyl methacrylate), P(MAPEG-co-MAA-co-MAPTMS)

Radical copolymerizations of P(MAPEG-co-MAA-co-MAPTMS) were initiated by ACPA at $70^{\circ} \mathrm{C}$, in the presence of a chain transfer agent $(\mathrm{BuSH})$. A typical experiment for the polymerization procedure (Table $1, \mathrm{P}\left(\mathrm{PEG}_{40}-\mathrm{MAA}_{30}-\mathrm{Si}_{30}\right)$ ) is as follows: in a $100 \mathrm{~mL}$ oneneck round-bottom flask, MAA (1.1809 g, $0.0136 \mathrm{~mol})$, MAPEG (20.0112 g, $0.0182 \mathrm{~mol})$, MAPTMS (3.3866 g, $0.0136 \mathrm{~mol})$ and ACPA (0.1281 g, $0.4545 \mathrm{mmol})$ were mixed with 40 $\mathrm{mL}$ of THF. The solution was bubbled under argon for $30 \mathrm{~min}$ at room temperature to remove free oxygen. BuSH $(0.97 \mathrm{~mL}, 0.009 \mathrm{~mol})$ was then injected into the mixture, using a microsyringe. The flask was then immersed in an oil bath thermostated at $70^{\circ} \mathrm{C}$ and the reaction was maintained for $24 \mathrm{~h}$ under argon. Polymers were directly isolated by evaporation of THF and then dried at room temperature under vacuum to yield a fine white powder.

\subsection{Cements and $C_{3} S$ used}

Two Portland cements named "Bussac" and "Couvrot" were used for this study. Chemical compositions are given in table 2. The main difference between the two cements comes from the sulfate alkali content which is much higher in "Couvrot" than in "Bussac".

Tricalcium silicate $\mathrm{C}_{3} \mathrm{~S}$ was synthesized at CTG Italcementi Group by calcination of stoechiometric mixture of $\mathrm{CaCO}_{3}$ and silica. $\mathrm{C}_{3} \mathrm{~S}$ was ground to a specific surface Blaine of $3900 \mathrm{~cm}^{2} \cdot \mathrm{g}^{-1}$.

\subsection{Synthesis of ettringite}


Ettringite was obtained by precipitation from solution containing stoechiometric mixture of burned $\mathrm{CaO}$ (obtained by calcination of $\mathrm{CaCO}_{3}$ for $12 \mathrm{~h}$ at $1000{ }^{\circ} \mathrm{C}$ ) and $\mathrm{Al}_{2}\left(\mathrm{SO}_{4}\right)_{3} \cdot 16 \mathrm{H} 2 \mathrm{O}$ in excess of deionized water. The reaction is as follows:

$6 \mathrm{CaO}+\mathrm{Al}_{2}\left(\mathrm{SO}_{4}\right)_{3} \cdot 16 \mathrm{H}_{2} \mathrm{O}+16 \mathrm{H}_{2} \mathrm{O} \rightarrow 3 \mathrm{CaO} \cdot \mathrm{Al}_{2} \mathrm{O}_{3} \cdot 3 \mathrm{CaSO}_{4} \cdot 32 \mathrm{H}_{2} \mathrm{O}$

After 7 days, the precipitate was washed with deionized water, filtered and then dried at $35^{\circ} \mathrm{C}$ for one day. X-ray diffraction (XRD) analysis confirmed the product to be ettringite.

\subsection{Preparation of cement pastes}

All cement pastes were prepared at room temperature with a W/C of 0.44 , using a IKA Labortechnik mixer equipped with a 4-bladed propeller stirrer. First of all, aqueous SP solutions were prepared with deionized water for the reference polycarboxylate $\mathrm{P}\left(\mathrm{PEG}_{60^{-}}\right.$ $\mathrm{MAA}_{40}$ ) or with $0.1 \mathrm{~N} \mathrm{NaOH}$ solution for all silylated SPs. Different amounts of $\mathrm{Na}_{2} \mathrm{SO}_{4}$ were added to the starting polymer aqueous solutions in order to study the effect of soluble sulfate ions on the adsorption and rheological behaviors. Then, the pastes were prepared by mixing the cement powder with the polymer solution for $1 \mathrm{~min}$ at low speed and a further 2 min at high speed. The same procedure was used for $\mathrm{C}_{3} \mathrm{~S}$ with $\mathrm{W} / \mathrm{C}=1$. For ettringite, the sample was prepared with $\mathrm{W} / \mathrm{C}=5$ and sample suspension was stirred for $15 \mathrm{~min}$ before being extracted.

\subsection{Analytical methods}

\subsubsection{Nuclear magnetic resonance (NMR)}

${ }^{1} \mathrm{H}$ NMR spectra of polymers was performed in $\mathrm{CDCl}_{3}$ at $25^{\circ} \mathrm{C}$ with a Bruker Avance 200 (200 MHz) spectrometer. Liquid and solid state ${ }^{29} \mathrm{Si}$ NMR experiments were carried out on a Bruker Avance $500 \mathrm{MHz}$ spectrometer in a $7 \mathrm{~mm}$ diameter probe. Triethylsilane and Q8M8 were used as reference for liquid and solid state experiments, respectively. For solid state NMR, cross-polarization magic angle spinning (CP-MAS) spectra were performed with a typical pulse length of $4 \mu \mathrm{s}$ at spinning rate of $7 \mathrm{kHz}$.

\subsubsection{Size exclusion chromatography}

The molar masses $\left(\mathrm{M}_{\mathrm{W}}\right.$, absolute values) and their distribution (PDI $=\mathrm{M}_{\mathrm{w}} / \mathrm{M}_{\mathrm{n}}$, the polydispersity index) were measured by size exclusion chromatography (SEC) coupled with a triple detection (light scattering, viscosity and refractive index). The measurements were 
performed at $35^{\circ} \mathrm{C}$ on a Shodex $\mathrm{OHpak}$ column from Waters Instruments using a $0.5 \mathrm{~mol} \mathrm{~L}{ }^{-1}$ $\mathrm{LiNO}_{3}$ aqueous solution ( $\mathrm{pH}$ adjusted to 12.6 with $\mathrm{NaOH}$ ) as eluent.

\subsubsection{Thermogravimetric analysis}

Thermogravimetric measurements (TGA) were carried out using an SDT 2960 analyzer from TA Instruments equipped with a flow gas system. Experiments were performed under $\mathrm{N}_{2}$ to $600{ }^{\circ} \mathrm{C}$ then under air to $1000{ }^{\circ} \mathrm{C}$, at a heating rate of $10{ }^{\circ} \mathrm{C} \cdot \mathrm{min}^{-1}$.

\subsubsection{Adsorption isotherms}

Adsorption of SP on cement, $\mathrm{C}_{3} \mathrm{~S}$ and ettringite was measured using a total organic carbon analyzer (TOC-V, Shimadzu). $15 \mathrm{~min}$ after the contact between the polymer solutions and the powders, the interstitial solution was extracted from the paste by centrifugation at $6000 \mathrm{rpm}$ for 10 min with a Hettich EBA 21 centrifuge, and filtered with a $0.45 \mu \mathrm{m}$ nylon filter. The adsorbed amount of SP was calculated from the difference between the organic content in initial mixing aqueous solution and in the filtrated interstitial solution. Values were corrected from the carbone amount released by cement mixed with pure water. SP adsorption measurements on cement were repeated twice using a new fresh paste each time.

\subsubsection{Rheological behavior}

Rheological measurements were conducted with an AR $1000 \mathrm{~N}$ controlled stress rheometer (TA Instruments), equipped with a double helix type geometry. The measurements were performed $15 \mathrm{~min}$ after mixing by preshearing the paste at a shear rate of $100 \mathrm{~s}^{-1}$ for $1 \mathrm{~min}$, followed by a steady-state measurement at several stress values decreasing from the stress value corresponding to a shear rate of $100 \mathrm{~s}^{-1}$ to $0.01 \mathrm{~Pa}$. The yield stress was calculated by fitting the rheogram data according to the Hershey-Buckley model.

\subsubsection{Setting}

The hydration of cement paste was followed at $20^{\circ} \mathrm{C}$ with a high sensitivity $(0.1 \mu \mathrm{W})$ isothermal Tian-Calvet type microcalorimeter (SETARAM M60). Before starting the experiment, the cement paste was prepared in a plastic cell with $2 \mathrm{~g}$ of cement at $\mathrm{W} / \mathrm{C}=0.44$ and at a dosage of SP/C equal to 0.1 mass $\%$ or to $0.3 \%$. The cell was quickly introduced in the calorimeter before measurement.

\subsubsection{Concrete equivalent mortar (CEM)}


Concrete equivalent mortars were prepared with "Bussac" and "Couvrot" cements to examine the influence of the sulfate alkali content included in cement powder on dosage requirement for SP. The mortar was prepared with $1350 \mathrm{~g}$ of normalized CEN sand, $679 \mathrm{~g}$ of cement and $303.3 \mathrm{~g}$ of water (20.9 $\mathrm{g}$ of water was used for pre-wetting the sand). The mixing protocol used was described by A. Schwartzentruber et al.[17] The minimum dosage of SP required to obtain a slump of $210 \mathrm{~mm} \pm 10 \mathrm{~mm}$ was determined for all mortars. Slump flow was measured by pull out spread of the mortar from a cone of top diameter $50 \mathrm{~mm}$, bottom diameter $100 \mathrm{~mm}$ and height $150 \mathrm{~mm}$ after 7 minutes of mixing. The spread was calculated from the average of three crossing diameters.

\section{Results and discussion}

\subsection{Synthesis and characterization of SPs}

A series of poly(poly(ethylene glycol) methyl ether methacrylate-co-methacrylic acid-cotrimethoxylsilyl proyl methacrylate), P(MAPEG-co-MAA-co-MAPTMS), with various compositions has been synthesized by radical co-polymerization in presence of a chain transfer agent. Chemical structures of the synthesized polymers are shown in Fig.1. The substitution of MAA by MAPTMS has been varied from 0 to $100 \mathrm{~mol} \%$ and the percentage of PEG side chains has been fixed to $40 \mathrm{~mol} \%$ for all polymers. The extreme compositions of the series correspond to on one side reference polyacrylate polymer (PC), $\mathrm{P}\left(\mathrm{PEG}_{40}-\mathrm{MAA}_{60}\right)$, and on the other side acrylate-free $\mathrm{SPs}, \mathrm{P}\left(\mathrm{PEG}_{40}-\mathrm{Si}_{60}\right)$. The principal characteristics (Mw and PDI) of the different SPs are summarized in Table 1.

The conversion of monomers during polymerization was followed by ${ }^{1} \mathrm{H}$ NMR by continuous measurement of the vinyl proton peaks of monomers. First, for the reference copolymer $\mathrm{P}\left(\mathrm{PEG}_{40}-\mathrm{MAA}_{60}\right)$, the consumption of both monomers followed the same kinetic during the polymerization suggesting a random distribution of MAA and PEG side chains along the polymer backbone. The attempt to extrapolate this result to the terpolymers P(MAPEG-coMAA-co-MAPTMS) was more complex due to the overlapping of the vinyl proton peaks of the three monomers. Despite this difficulty, we observed in all cases a conversion of monomers more than $96 \%$ after $24 \mathrm{~h}$ of reaction by comparing the integration of all the vinyl protons peaks relative to those of PEG side chains $\left(-\mathrm{O}-\mathrm{CH}_{3}\right)$. The conversion yield close to $100 \%$ justifies the fact that SPs may be used directly after evaporation of the solvent without further purification. We suppose that the residual polymerization reagents present after drying have no influence on the properties of the polymers. 
The expected amount of alkoxysilanes included in SPs has been confirmed by TGA and by quantitative ${ }^{29} \mathrm{Si}$ NMR carried out in the crude solution of reaction. During polymerization, the formation of a little amount of methanol was observed by ${ }^{1} \mathrm{H}-\mathrm{NMR}$ indicating a partial hydrolysis of the trimethoxysilane functions into silanols. Such hydrolysis could not be avoided even in dry condition using distilled THF solvent. ${ }^{29} \mathrm{Si}$ NMR spectroscopy was carried out to characterize the condensation of partially hydrated trialkoxysilane in the crude reaction mixture and then after drying (see Fig.2). In liquid state, ${ }^{29} \mathrm{Si} \mathrm{NMR}$ spectrum is characterized by a main peak at $-42.7 \mathrm{ppm}$ corresponding to un-condensed $\mathrm{T}^{0}\left(\mathrm{C}-\mathrm{Si}(\mathrm{OR})_{3}\right.$; $\mathrm{R}=\mathrm{CH}_{3}$ or $\mathrm{H}$ ) species. After drying, in addition to $\mathrm{T}_{0}$ environment, several organosilanes are condensed in the form of $\mathrm{T}_{1}\left(\mathrm{C}-\mathrm{Si}(\mathrm{OSi})_{1}(\mathrm{OR})_{2}, \delta=-50.1 \mathrm{ppm}\right)$ and $\mathrm{T}_{2}\left(\mathrm{C}-\mathrm{Si}(\mathrm{OSi})_{2}(\mathrm{OR})_{1}, \delta=\right.$ $-59.1 \mathrm{ppm})$ species.[18] It appears that the drying step under reduced pressure caused inevitably the formation of inter or intrachain siloxane bridges. The condensation of alkoxysilane may explain why the dried silylated polymers can neither be redispersed in THF nor in pure water. However, the aqueous dispersion of the polymers is made possible by using $\mathrm{NaOH}$ solution at $\mathrm{pH}$ between 12 and 13 due to the instability of siloxane bridges in basic medium. Moreover, hydrolysis of residual trimethoxysilane is mainly facilitated at high pH.[19] The good dispersion of silylated SPs in $\mathrm{NaOH}$ solution was confirmed by comparing the hydrodynamic radius determined by dynamic light scattering measurements of $\mathrm{P}\left(\mathrm{PEG}_{40^{-}}\right.$ $\mathrm{Si}_{60}$ ) and reference PC. Very similar hydrodynamic radius, $4.5 \mathrm{~nm}$ and $5.2 \mathrm{~nm}$, were obtained for both copolymers respectively, confirming the disappearance of interchain siloxane bonds in alkaline medium.

\subsection{Adsorption isotherms}

The adsorption isotherms of $\mathrm{P}\left(\mathrm{PEG}_{40}-\mathrm{MAA}_{60}\right)$ and $\mathrm{P}\left(\mathrm{PEG}_{40}-\mathrm{MAA}_{40}-\mathrm{Si}_{20}\right)$ on the low sulfate alkali "Bussac" cement after 15 minutes of reaction are shown as examples in Fig. 3. The amount of adsorbed polymers increases gradually with the concentration of superplasticizers and then tends to saturate at SP/C higher than $0.2 \%$. In the following and in order to limit the number of experiments, a $\mathrm{SP} / \mathrm{C}=0.3 \%$ value was chosen as a single adsorption measurement to access the adsorption capacity of each polymer in different experimental conditions.

\subsection{Effects of alkoxysilane groups on SP adsorption}

The substitution of carboxyl by trialkoxysilane groups has a strong impact on the adsorption amount of SPs on cement. As seen in Fig.4, the adsorption is enhanced by more than a 1.5 
factor for a carboxyl-organosilane substitution of about $20 \%$ and then gradually decreases for higher substitution. The adsorption of carboxyl-free polymer, $\mathrm{P}\left(\mathrm{PEG}_{40}-\mathrm{Si}_{60}\right)$, is slightly lower than for the reference PC. To characterize the influence of sulfate ions on the adsorption properties, measurements have been repeated in presence of $140 \mathrm{mmol} . \mathrm{L}^{-1}$ and $200 \mathrm{mmol. \textrm {L } ^ { - 1 }}$ of $\mathrm{Na}_{2} \mathrm{SO}_{4}$ added in the starting aqueous solution. To access to the real sulfate amount in cement paste during adsorption which depends on the chemical equilibrium reaction during hydration and on the initial content of sulfate alkali in cement powder, interstitial solution has been extracted after 15 minutes and analyzed by Inductively Coupled Plasma (ICP). These experiments have been conducted on polymer-free mixes and it was assumed that the obtained values were not influenced by the presence of SP. With an extra addition of 140 mmol.L $\mathrm{L}^{-1}$ and 200 mmol.L-1 of $\mathrm{Na}_{2} \mathrm{SO}_{4}$, the sulfate ion concentration after 15 minutes which is initially equal to $26 \mathrm{mmol} . \mathrm{L}^{-1}$ for the "Bussac" cement goes from $145 \mathrm{mmol.L} \mathrm{L}^{-1}$ to 195 mmol. $\mathrm{L}^{-1}$, respectively. As expected [12], an increase of sulfate ions in solution induced a partial desorption of the reference $\mathrm{PC}$; the adsorption amount of $\mathrm{P}\left(\mathrm{PEG}_{60}-\mathrm{MAA}_{40}\right)$ falls from $1.1 \mathrm{mg} . \mathrm{g}^{-1}$ to less than $0.5 \mathrm{mg} \cdot \mathrm{g}^{-1}$ of cement by addition of $140 \mathrm{mmol} . \mathrm{L}^{-1}$ of sodium sulfate. However, as substitution of carboxyl by alkoxysilane increases, the adsorption is less and less influenced by the presence of sulfate ions. This important result shows that the modification of polycarboxylate superplasticizers by the insertion of a few triethoxysilane groups allows a substantial improvement of adsorption stability in presence of sulfate ions in the interstitial solution.

\subsection{Adsorption on pure phases}

In order to improve understanding of adsorption mechanism of silylated SP on cement, adsorptions experiments have been investigated on silicate tricalcium $\mathrm{C}_{3} \mathrm{~S}$ and ettringite phases. These both phases have been chosen as representative of silicate phases on one side and aluminate phases on the other. Because anhydrous $\mathrm{C}_{3} \mathrm{~A}$ and $\mathrm{C}_{4} \mathrm{AF}$ phases are highly reactive in water, we preferred to use ettringite which is the principal aluminate hydrates formed at the early stage of hydration. As seen in Fig.5, reference PC strongly adsorbs on ettringite probably via ionic interaction between $\mathrm{COO}^{-}$with the ettringite positively charged surface.[20] The interaction of hydroxysilane groups, partially deprotonated at high $\mathrm{pH}$, with ettringite is less effective and the polymer adsorption decreases by a factor more than 3 for the fully silylated polymer, $\mathrm{P}\left(\mathrm{PEG}_{40}-\mathrm{Si}_{60}\right)$. Whatever the composition of SPs, the adsorption onto ettringite falls down by addition of sulfate ions. The adsorption behavior on $\mathrm{C}_{3} \mathrm{~S}$ is radically different. The adsorption of SPs on $\mathrm{C}_{3} \mathrm{~S}$ is improved by the substitution of 
carboxylate by silylated functions suggesting a stronger interaction of the second species compared to the first ones. Moreover, with a sodium sulfate addition $\left(100 \mathrm{mmol} . \mathrm{L}^{-1}\right)$ in the aqueous solution, the adsorption of the reference PC falls down to zero, whereas it remains high in silylated SPs. We can note for these modified SPs that the adsorption value does not depend on the level of substitution. These results are coherent with published data by Franceschini et al.[16] of adsorption measurements of trialkoxysilane-modified polymers as polyvinylpyrolidone or polydimethylacrylamide onto $\mathrm{CSH}$. It was demonstrated in this previous work the formation of covalent bonds between the silicate inorganic chains of CSH and the silylated functions. Moreover, the efficiency of the linkage is such that only few percents of these functions were sufficient to ensure strong adsorption on CSH. These results can be manifestly extrapolated in this work to the adsorption on $\mathrm{C}_{3} \mathrm{~S}$ phase which is quickly covered by a layer of hydration product during the initial reaction of hydration [21]. At the difference of ionic bonds formed between acrylates and $\mathrm{C}_{3} \mathrm{~S}$ (or $\mathrm{CSH}$ ) which are easily displaced by sulfates ions, siloxane-CSH bonds are strong enough to avoid being destroyed by addition of sulfate ions.

Thanks to adsorption measurements on $\mathrm{C}_{3} \mathrm{~S}$ and ettringite, it becomes possible to explain the adsorption behavior of silylated SPs on cement. By replacing a low fraction of carboxylate by alkoxysilane, the adsorption property of SP is improved by formation of strong bonds with $\mathrm{CSH}$. The carboxylate groups allow also an adsorption on aluminates. However, the addition of sulfate ions induces a partial desorption of polymers, especially from aluminates. An increase of alkoxysilane substitution causes a partial loss of adsorption due to reduced interactions with aluminates. As the adsorption occurs now mainly on silicate phases, the displacement by sulfate ions is strongly suppressed.

\subsection{Rheological properties}

The effects of silylated SP on the fluidity of cement paste in function of the soluble sulfate concentration have been investigated (Fig.6). Without extra addition of sodium sulfate (data corresponding to sulfate concentration of $26 \mathrm{mmol} . \mathrm{L}^{-1}$ ), all the adjuvanted cement pastes show good dispersing properties (yield stress $<5 \mathrm{~Pa}$ ) compared to polymer-free paste (yield stress $=92 \mathrm{~Pa})$, except for fully silylated $\mathrm{SP}, \mathrm{P}\left(\mathrm{PEG}_{40}-\mathrm{Si}_{60}\right)$. As discussed above, $\mathrm{P}\left(\mathrm{PEG}_{40^{-}}\right.$ $\left.\mathrm{Si}_{60}\right)$ is preferentially adsorbed onto silicates phases. It is likely that the inhomogeneity of adsorption makes this polymer less effective against flocculation. As expected, when extra sulfate ions are introduced, the dispersing ability of reference PC decreases significantly due to a reduced adsorption. The dispersing abilities of silylated SP is less impacted by sulfate 
competition, especially for the SPs made with more than 20 mol\% of trialkoxysilane, which is consistent with an adsorption which is less affected by sulfates in solution.

\subsection{Setting}

In complement to this work, the influence of polymer composition on the setting time of "Bussac" cement has been carried out at a SP dosage of 0.1 mass $\%$ and 0.3 mass\% (see Fig.7). For the low dosage in polymer, the setting retardation of few hours, compared to non adjuvanted cement paste, depends weakly on the acrylate-alkoxysilane ratio. Nevertheless, at a dosage of 0.3 mass \%, more significant retardation is observed for silylated SPs compared to reference PC. Curiously, the setting time is becoming shorter as the organosilane substitution increases. However, this effect seems to be correlated to the adsorption behavior which follows the same trend; superplasticizers incorporating too much alkoxysilane adsorb less effectively and then the retard effect which is impacted by adsorption is less important. Once the cement has begun to set, compared to PC, all the silylated polymers tend to accelerate the precipitation of hydrates. Currently, we have no explanation of this effect but one can think that the nature of reactive groups (acrylate vs. silanol) linked to the SPs may drastically influence the mechanisms of nucleation and grain growth of hydrates.

\subsection{Concrete equivalent mortar}

We have shown that the modification of SP by insertion of trialkoxysilane groups mainly reduced the problem of sulfate competition. However, until now this assertion has be demonstrated using a single cement and by varying the concentration of sodium sulfate added in aqueous solution. To make these adjuvants attractive for practical use, the compatibility with different cements must be established. We must demonstrate that for a required rheological property, the SP dosage is independent on the amount of sulfate initially included in cement powder. To answer to this interrogation, concrete equivalent mortars have been designed with two Portland cements differing by their sulfate alkali content (see Tab.2). $\mathrm{P}\left(\mathrm{PEG}_{40}-\mathrm{MAA}_{60}\right)$ and $\mathrm{P}\left(\mathrm{PEG}_{40}-\mathrm{MAA}_{40}-\mathrm{Si}_{20}\right)$ have been used to improve workability and the amount of each SP has been determined in order to achieve a slump of $210 \mathrm{~mm} \pm 10 \mathrm{~mm}$ (standard OA 400 formula). The required dosage of $\mathrm{P}\left(\mathrm{PEG}_{40}-\mathrm{MAA}_{60}\right)$ in mortar increases more than twice for the low alkali cement than for the high alkali cement. On the contrary,

the dosage of $\mathrm{P}\left(\mathrm{PEG}_{40}-\mathrm{MAA}_{40}-\mathrm{Si}_{20}\right)$ remains the same for both mortars demonstrating the excellent performance of silylated SP with respect to the sulfate compatibility. 


\section{Conclusion}

A series of polycarboxylate based superplasticizers modified with trialkoxysilane functions have been successfully synthesized by radical copolymerization. The adsorption on cement and the dispersing properties have been investigated in function of the polymer composition and at different concentration of soluble sulfate ions in solution. It was found that a partial substitution of carboxylic by alkoxyde functions enhances the adsorption. However, an excess of silylated functions is detrimental for the adsorption. Inclusion of a small amount of alkoxysilane into polycarboxylate polymers greatly reduced the competition of adsorption with sulfate ions. It was recognized that silylated functions interact essentially with silicate phases and form strong bounds which are insensible of sulfate ions. The strong correlation between the adsorption level and dispersing ability make the silylate-modified polycarboxylates very promising to improve the formulation robustness of concretes made with cements containing various amount of sulfate alkali.

\section{Acknowledgement}

We acknowledge the Agence Nationale de la Recherche et de la Technologie for financial support. We are grateful to M. Hanafi for help with GPC measurements.

\section{References}

[1] P.-C. Aïtcin, C. Jolicoeur, J.G. MacGregor, Superplasticizers: How They Work and Why They Occasionally Don’t, Concrete International 16 (5) (1994) 45-52.

[2] K. Yoshioka, E. Sakai, M. Daimon, A. Kitahara, Role of steric hindrance in the performance of superplasticizers for concrete, J. Am. Ceram. Soc. 80 (10) (1997) 2667-2671. [3] C. Jolicoeur, M.A. Simard, Chemical admixture-cement interactions: Phenomenology and physico-chemical concepts, Cem Concr Compos, 20 (1998) 87-101.

[4] S. Hanehara, K. Yamada, Interaction between cement and chemical admixture from the points of cement hydration, admixture adsorption and paste rheology, Cem Concr Res 29 (1999) 1159-1165.

[5] E. Sakai, K. Yamada, A. Ohta, Molecular Structure and Dispersion-Adsorption Mechanisms of Comb-Type Superplasticizers Used in Japan, Journal of Advanced Concrete Technology, 1 (1) (2003) 16-25. 
[6] D. Bonen, S.L. Sakar, The superplasticizer adsorption capacity of cement paste, pore solution composition, and parameters affecting flow loss, Cem Concr Res 25 (1995) 14231434.

[7] E. Tazawa, B. Mtasiwa, M. Takahashi, Effect of types of superplasticizers and mixing methods on the properties of cementitious systems, Proceedings Fifth CANMET/ACI International Conference Rome, Superplasticizers and Other Chemical Admixtures in Concrete (1997) 637- 656.

[8] R.J. Flatt, Y.F. Houst, A simplified view on chemical effects perturbing the action of superplasticizers, Cem Concr Res, 31 (2001) 1169-1176.

[9] R.J. Flatt, Towards a prediction of superplasticized concrete rheology, Mater Struct, 37 (2004) 289-300.

[10] K. Yamada, S. Hanehara, Intraction mechanism of cement and superplasticizers - The roles of polymer adsorption and ionic conditions of aqueous phase, Concr Sci Eng, 3 (2001) $135-145$.

[11] R.J. Flatt, Y.F. Houst, P. Bowen, H. Hofmann, J. Widmer, U. Sulser, U. Maeder, T.A. Btirge, Interaction of superplasticizers with model powders in a highly alkaline medium, Proc. 5 r Canmet/ACI Int. Conf. on Superplasticizers and Other Chemical Admixtures in Concrete, Ed: Malhotra V.M., (American Concrete Institute, Farmington Hills, Mi, USA, 1997, SP-173) 743-762.

[12] K. Yamada, S. Ogawa, S. Hanehara, Controlling the Adsorption and Dispersing Force of Polycarboxylate-Type Superplasticizer by Sulfate Ion Concentration in Aqueous Phase, Cem. Concr. Res. 31 (2001) 375-383.

[13] J. Zimmermann, C. Hampel, C. Kurz, L. Frunz, R.J. Flatt, Effect of Polymer Structure on the Sulfate-Polycarboxylate Competition, Ninth ACI International Conference on Superplasticizers and Other Chemical Admixtures in Concrete, SP-262 (2009) 165-175.

[14] R.J. Flatt, J. Zimmermann, C. Hampel, C. Kurz, L. Frunz C. Plassard, E. Lesniewska, The role of Adsorption Energy in the Sulfate-Polycarboxylate Competition, Ninth ACI International Conference on Superplasticizers and Other Chemical Admixtures in Concrete, SP-262 (2009) 153-164.

[15] J. Minet, S. Abramson, V. Mancini, B. Bresson, C. Sanchez, V. Montouillout N. Lequeux, Chem. Mater. , 16 (2004) 3955-3962.

[16] A. Franceschini, S. Abramson, V. Mancini, B. Bresson, C. Chassenieux, N. Lequeux, New covalent bonded polymer-calcium silicate hydrate composites, J Mater Chem, 17 (2007) 913-922. 
[17] A. Schwartzentruber, C. Catherine, Method of the concrete equivalent mortar (CEM) - A new tool to design concrete containing admixture, Mater. Struct., 2000 (33) 475-482.

[18] R. J. Hook, A ${ }^{29} \mathrm{Si}$ NMR study of the sol-gel polymerisation rates of substituted ethoxysilanes, J. Non-Cryst. Solids, 1996, 195,1.

[19] Sol-Gel Science: The Physics and Chemistry of Sol-Gel Processing, C. J. Brinker and G. W. Scherer, Academic Press, San Diego, USA,1989.

[20] A. Zingg, F. Winnefeld, L. Holzer, J. Pakusch, S. Becker, L. Gau, Adsorption of polyelectrolytes and its influence on the rheology, zeta potential, and microstructure of various cement and hydrate phases, J. Colloid Interface Sci, 2008 (323) 301-312.

[21] Taylor, H. F. W. (1997). Cement Chemistry, Thomas Telford. 
Table 1

Structural characteristics of synthesized polymers

\begin{tabular}{|c|c|c|c|c|c|c|c|c|c|c|c|}
\hline & \multicolumn{3}{|c|}{ Initial Mol\% } & \multirow{2}{*}{$\begin{array}{c}{ }^{\mathrm{NMR}}{ }^{1} \mathrm{H} \\
\mathrm{PEG} \\
\mathrm{mol} \%\end{array}$} & \multirow{2}{*}{$\begin{array}{c}\begin{array}{c}\text { Acid- } \\
\text { base } \\
\text { titration }\end{array} \\
\mathrm{COOH} \\
\text { mol\% }\end{array}$} & \multicolumn{2}{|c|}{$\mathrm{NMR}^{29} \mathrm{Si}^{\mathrm{a}}$} & \multicolumn{2}{|c|}{ TGA } & \multirow[b]{2}{*}{$\begin{array}{c}M_{w} \\
(\mathrm{kDa})\end{array}$} & \multirow[b]{2}{*}{$\begin{array}{c}\text { PDI } \\
M_{w} / M_{n}\end{array}$} \\
\hline & MAPEG & MAA & MAPTS & & & $\begin{array}{c}\text { Ratio } \\
\text { «MAPTMS / } \\
\text { TES » } \\
\text { expected }\end{array}$ & $\begin{array}{c}\text { Ratio } \\
\text { «MAPTMS / } \\
\text { TES » } \\
\text { measured }\end{array}$ & $\begin{array}{l}\mathrm{wt} \% \mathrm{SiO}_{2} \\
\text { calculated }\end{array}$ & $\begin{array}{l}\mathrm{wt} \% \mathrm{SiO}_{2} \\
\text { measured }\end{array}$ & & \\
\hline$P\left(P G_{40}-M A A_{60}\right)$ & 40 & 60 & 0 & 42 & 61 & - & - & - & - & 78 & 1.9 \\
\hline P(PEG $\left.{ }_{40}-\mathbf{M A A}_{55}-\mathrm{Si}_{5}\right)$ & 40 & 55 & 5 & - & - & 0.03 & 0.03 & $0.56-0.58$ & 0.54 & 83 & 1.4 \\
\hline $\mathbf{P}\left(\mathbf{P E G}_{40}-\mathrm{MAA}_{50}-\mathrm{Si}_{10}\right)$ & 40 & 50 & 10 & - & - & 0.05 & 0.05 & $1.18-1.20$ & 1.15 & 69 & 1.3 \\
\hline $\mathbf{P}\left(\mathbf{P E G}_{40}-\mathbf{M A A _ { 4 0 } - \mathbf { S i } _ { 2 0 } )}\right.$ & 40 & 40 & 20 & - & - & 0.16 & 0.15 & $2.29-2.35$ & 2.32 & 56 & 1.6 \\
\hline $\mathbf{P}\left(\mathbf{P E G}_{40}-\mathbf{M A A _ { 3 0 } - \mathbf { S i } _ { 3 0 } )}\right.$ & 40 & 30 & 30 & - & - & 0.26 & 0.27 & $3.33-3.46$ & 3.37 & 67 & 1.9 \\
\hline $\mathbf{P}\left(\mathbf{P E G}_{40}-\mathbf{M A A _ { 2 0 } - \mathbf { S i } _ { 4 0 } )}\right.$ & 40 & 20 & 40 & - & - & 0.31 & 0.30 & $4.50-4.65$ & 4.54 & - & - \\
\hline $\mathbf{P}\left(\mathbf{P E G}_{40}-\mathbf{M A A _ { 1 0 } - \mathbf { S i } _ { 5 0 } )}\right.$ & 40 & 10 & 50 & - & - & 0.38 & 0.37 & $5.63-5.82$ & 5.67 & - & - \\
\hline $\mathbf{P}\left(\mathbf{P E G}_{40}-\mathbf{S i}_{60}\right)$ & 40 & 0 & 60 & - & - & 0.44 & 0.42 & $6.75-6.98$ & 6.71 & 133 & 1.9 \\
\hline
\end{tabular}

${ }^{a} \mathrm{NMR}^{29} \mathrm{Si}$ analysis was performed for the final solution of polymerization using triethylsilane (TES) as internal standard.

${ }^{\mathrm{b}}$ Theoretical mass of $\mathrm{SiO}_{2}$ calculated with hypothesis of no hydrolysis and complete hydrolysis of alkoxysilane functions, respectively.

Table 2

Phase and chemical composition of the Portland cement used

\begin{tabular}{cccccccc}
\hline $\begin{array}{c}\text { Cement } \begin{array}{c}\mathrm{C}_{3} \mathrm{~S} \\
\text { type }\end{array} \\
(\mathrm{wt} \%)\end{array}$ & $\begin{array}{c}\mathrm{C}_{2} \mathrm{~S} \\
(\mathrm{wt} \%)\end{array}$ & $\begin{array}{c}\mathrm{C}_{3} \mathrm{~A} \\
(\mathrm{wt} \%)\end{array}$ & $\begin{array}{c}\mathrm{C}_{4} \mathrm{AF} \\
(\mathrm{wt} \%)\end{array}$ & $\begin{array}{c}\mathrm{Na}_{2} \mathrm{O}_{\mathrm{eq}} \\
(\mathrm{wt} \%)\end{array}$ & $\begin{array}{c}\mathrm{SO}_{3} \\
(\mathrm{wt} \%)\end{array}$ & $\begin{array}{c}\text { Specific surface Blaine } \\
\left(\mathrm{cm}^{2} \cdot \mathrm{g}^{-1}\right)\end{array}$ \\
\hline Bussac & 57.6 & 20.5 & 3.6 & 13.1 & 0.15 & 2.5 & 4120 \\
Couvrot & 67.1 & 8.7 & 14 & 4 & $\mathrm{x}$ & $\mathrm{x}$ & $\mathrm{X}$ \\
\hline
\end{tabular}




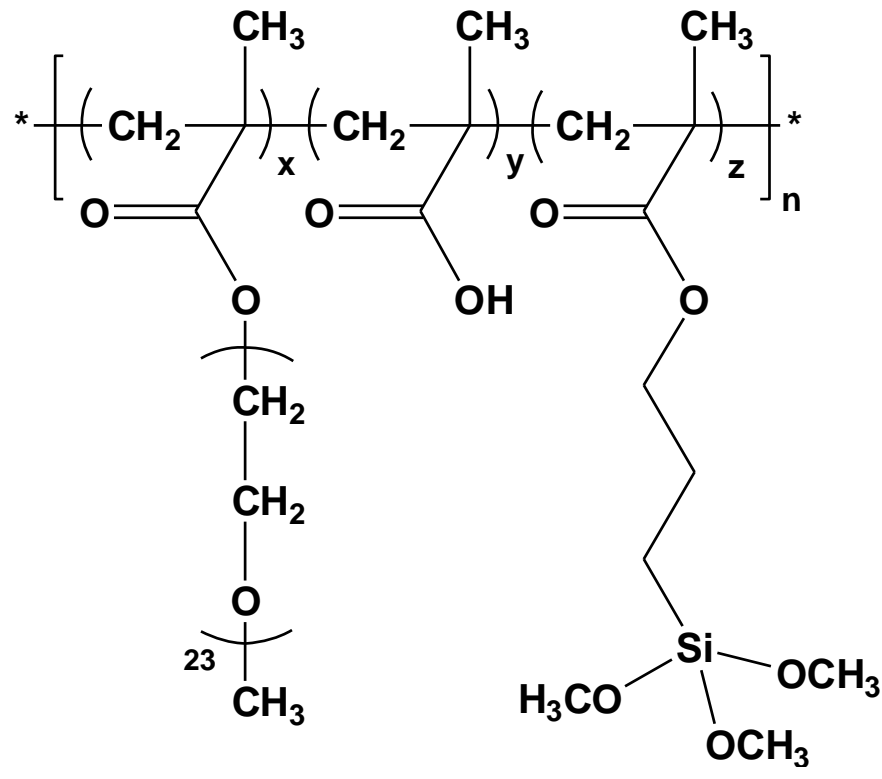

Fig. 1. Chemical structure of poly(poly(ethylene glycol) methyl ether methacrylate-co-methacrylic acid-co-3-(trimethoxylsilyl) proyl methacrylate), P(MAPEG-co-MAA-co-MAPTMS) 


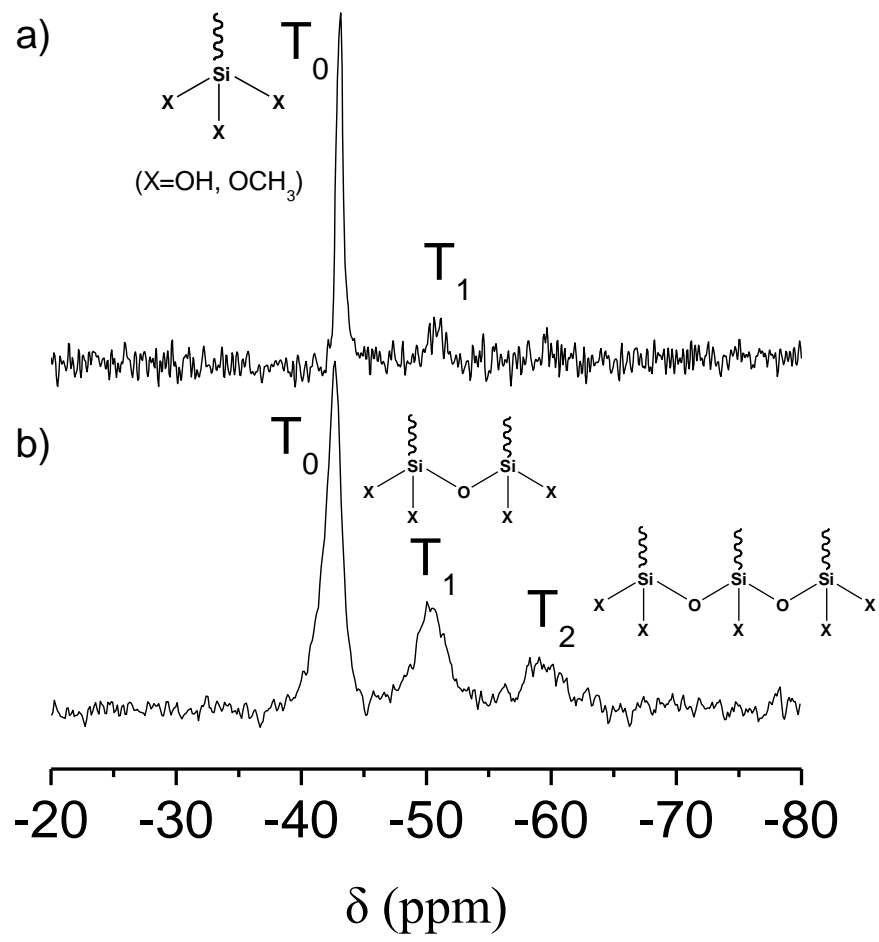

Fig.2. (a) liquid ${ }^{29} \mathrm{Si} \mathrm{NMR}$ of raw solution of $\mathrm{P}\left(\mathrm{PEG}_{40}-\mathrm{MAA}_{30}-\mathrm{Si}_{30}\right)$ after polymerization. (b) Solid ${ }^{29} \mathrm{Si}$ MAS NMR of $\mathrm{P}\left(\mathrm{PEG}_{40}-\mathrm{MAA}_{30}-\mathrm{Si}_{30}\right)$ after evaporation of THF solvent. 


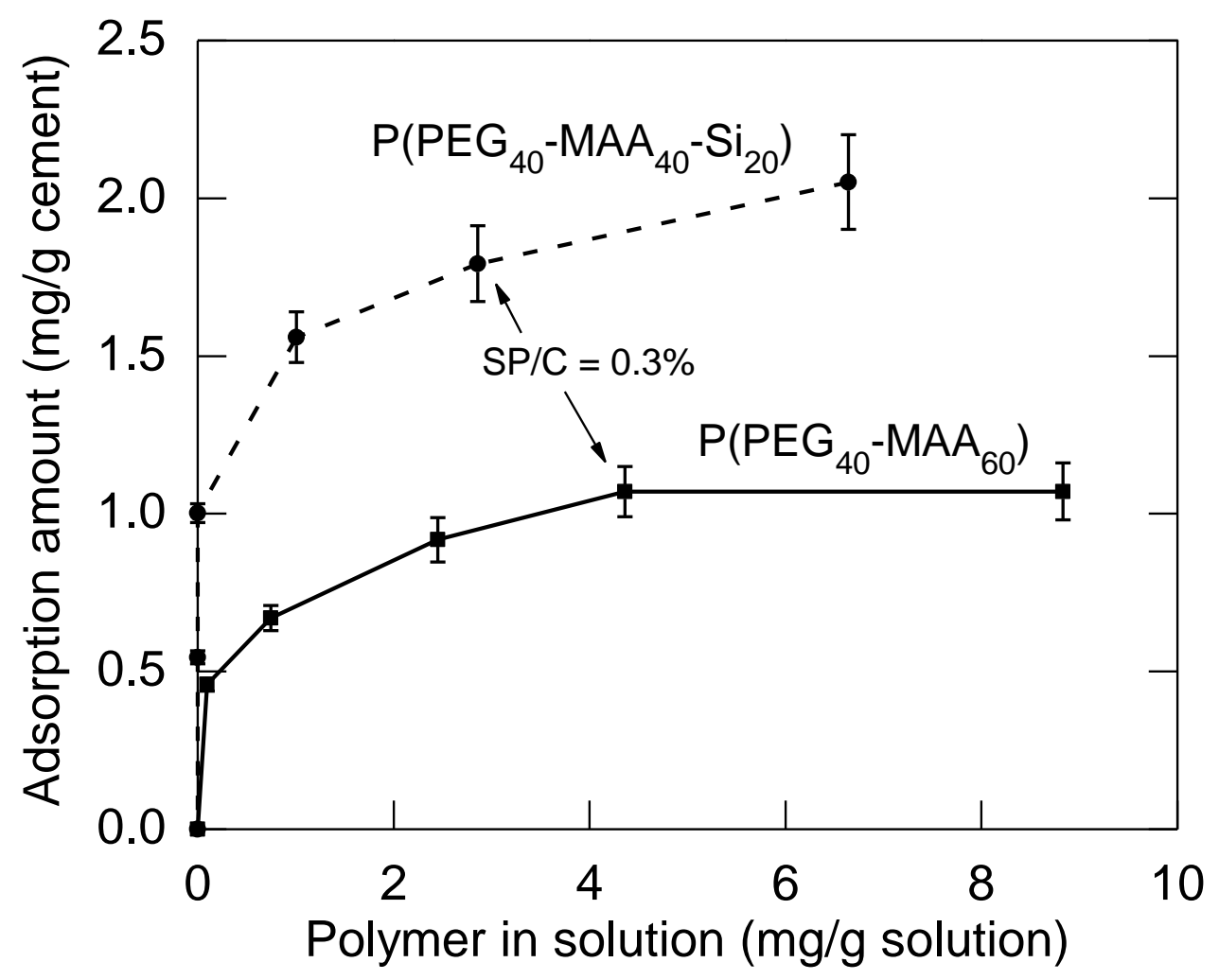

Fig. 3. Adsorption isotherms of $\mathrm{P}\left(\mathrm{PEG}_{40}-\mathrm{MAA}_{60}\right)$ and $\mathrm{P}\left(\mathrm{PEG}_{40}-\mathrm{MAA}_{40}-\mathrm{Si}_{20}\right)$ on "Bussac" cement $(\mathrm{W} / \mathrm{C}=0.44, \mathrm{t}=15 \mathrm{~min})$. 


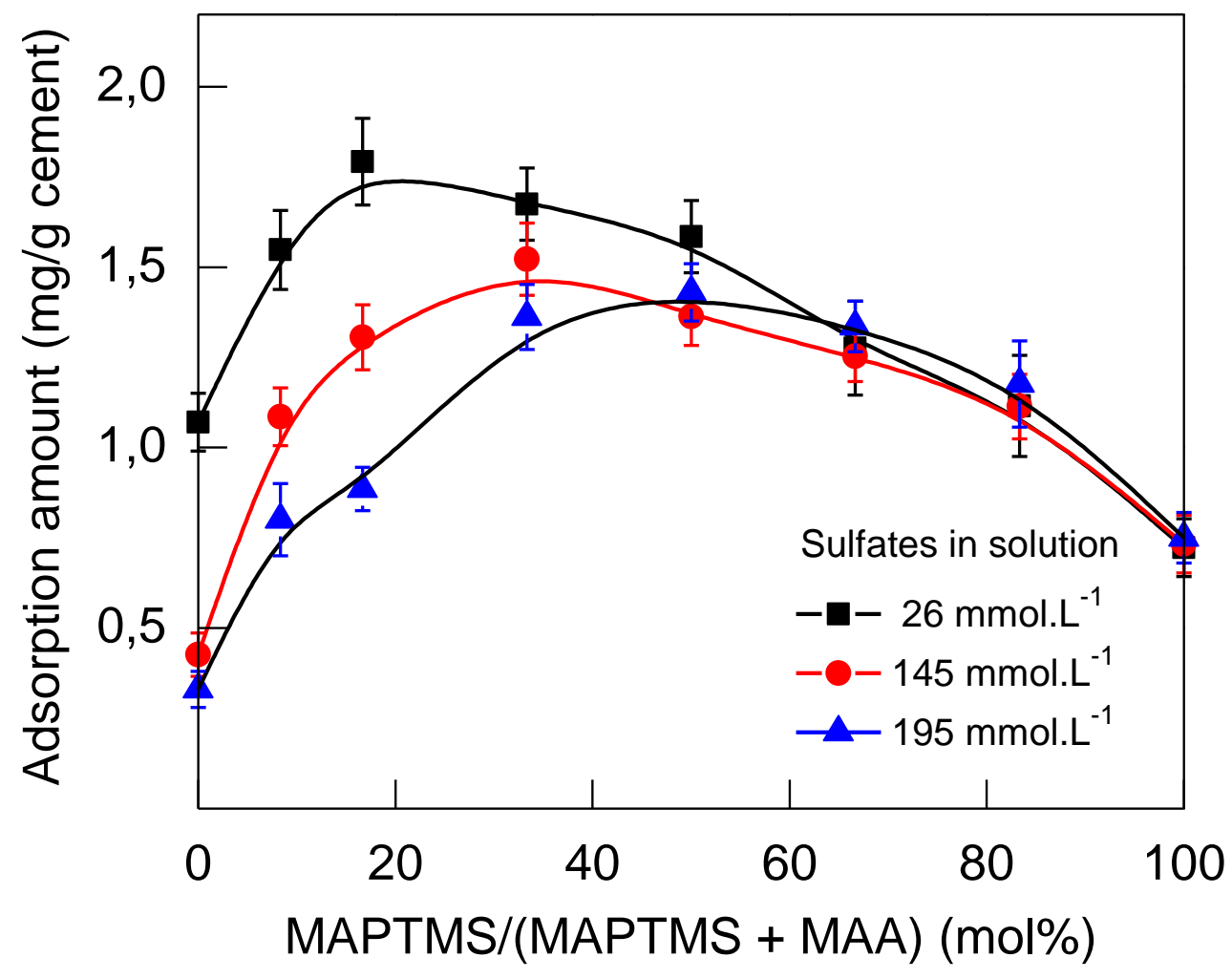

Fig. 4. Adsorption of P(MAPEG-co-MAA-co-MAPTS) on "Bussac" cement vs. the substitution percentage of MAA by MAPTS and for different amount of sulfate ions in solution after 15 minutes of setting. Black solid squares; adsorption on cement without ultra addition of $\mathrm{Na}_{2} \mathrm{SO}_{4}$ in starting solution. Red solid circles; adsorption on cement initially mixed with a 140 mmol. $\mathrm{L}^{-1}$ of $\mathrm{Na}_{2} \mathrm{SO}_{4}$ solution. Blue solid triangles; adsorption on cement initially mixed with a 200 mmol.L $\mathrm{L}^{-1}$ of $\mathrm{Na}_{2} \mathrm{SO}_{4}$ solution. All the measurements have been done with a $\mathrm{W} / \mathrm{C}=0.44$ and a $\mathrm{SP} / \mathrm{C}=0.3$ mass $\%$ after 15 minutes of hydration. The concentration of sulfate measured by ICP after 15 minutes is given in the figure. 


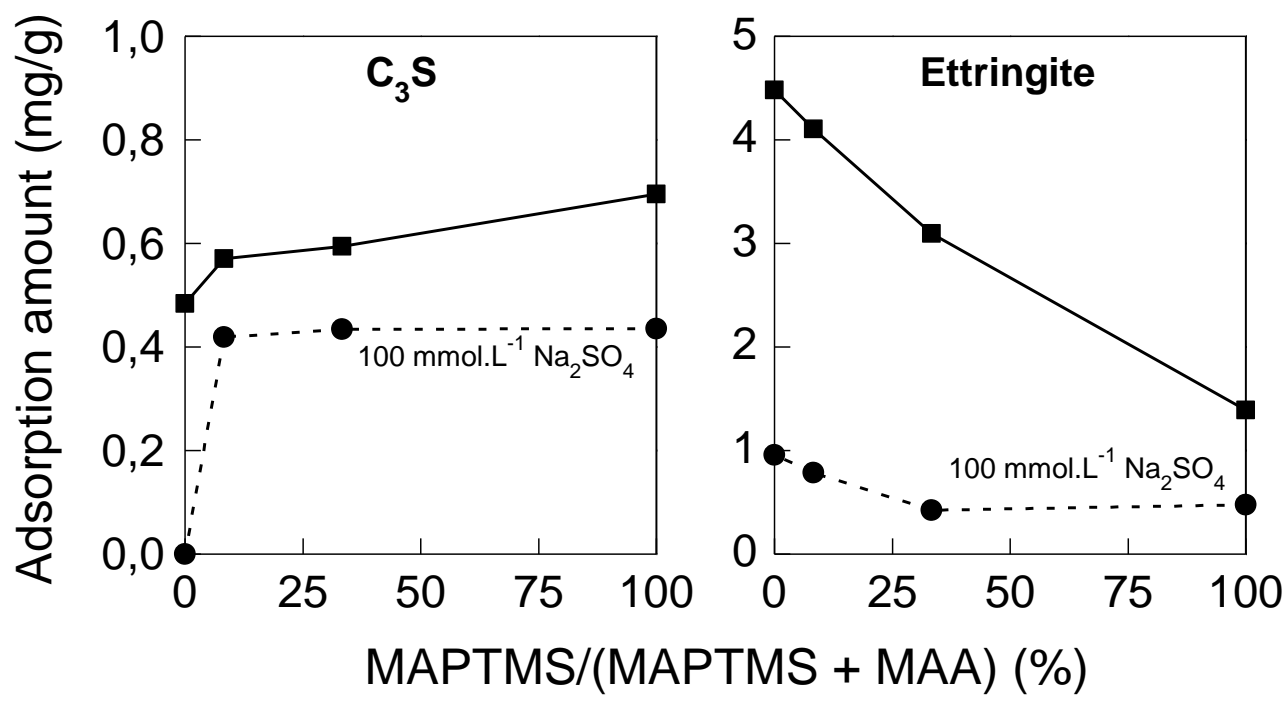

Fig. 5. Adsorption of SPs on $\mathrm{C}_{3} \mathrm{~S}$ and ettringite without addition of soluble sulfate ions (squares); and with addition of $100 \mathrm{mmol} . \mathrm{L}^{-1}$ of $\mathrm{Na}_{2} \mathrm{SO}_{4}$ (circles). Measurements have been done with $\mathrm{W} / \mathrm{C}=1$ and $\mathrm{SP} / \mathrm{C}=0.2$ for $\mathrm{C}_{3} \mathrm{~S}$ and $\mathrm{W} / \mathrm{C}=5$ and $\mathrm{SP} / \mathrm{C}=1$ for ettringite. All polymers were dissolved in $10^{-1} \mathrm{Mol} \mathrm{NaOH}$ solution. 


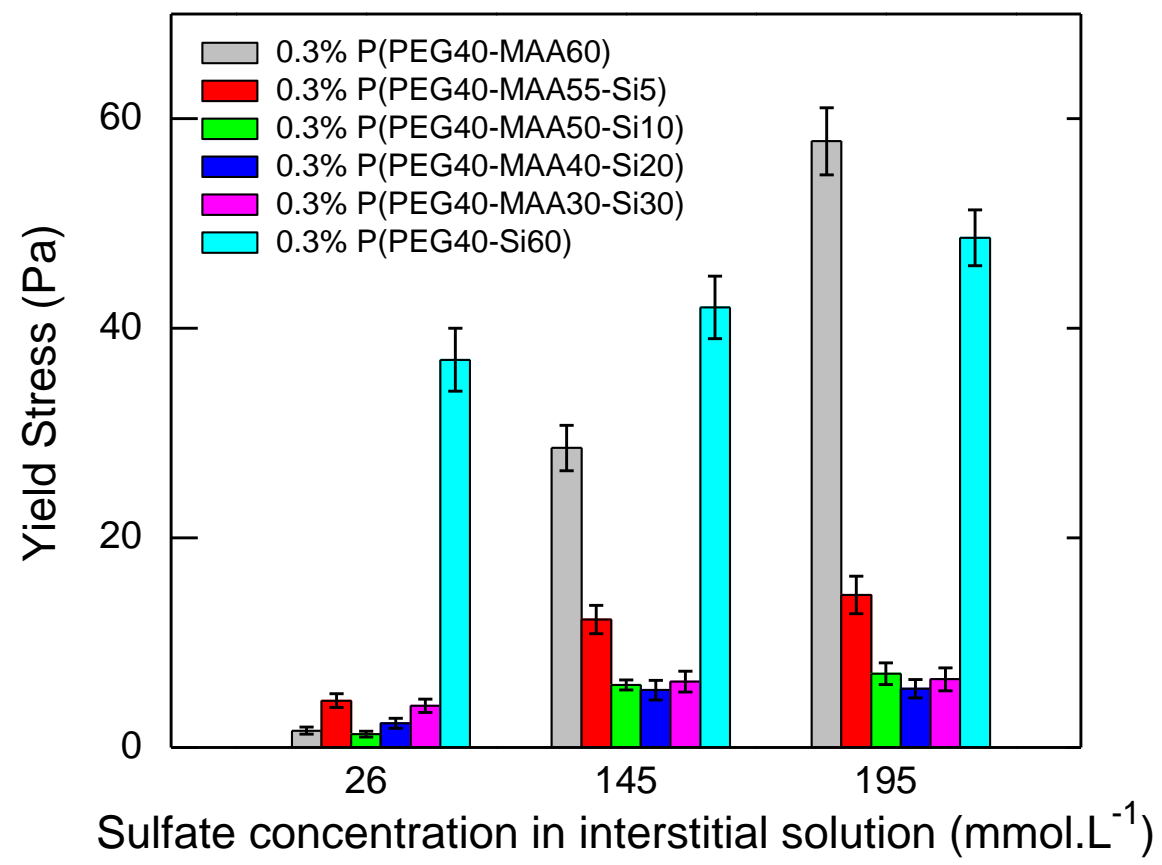

Fig. 6. Yield stress values of "Bussac" cement paste formulated with 0.3 mass $\%$ of SPs vs. the sulfate concentration in solution. 

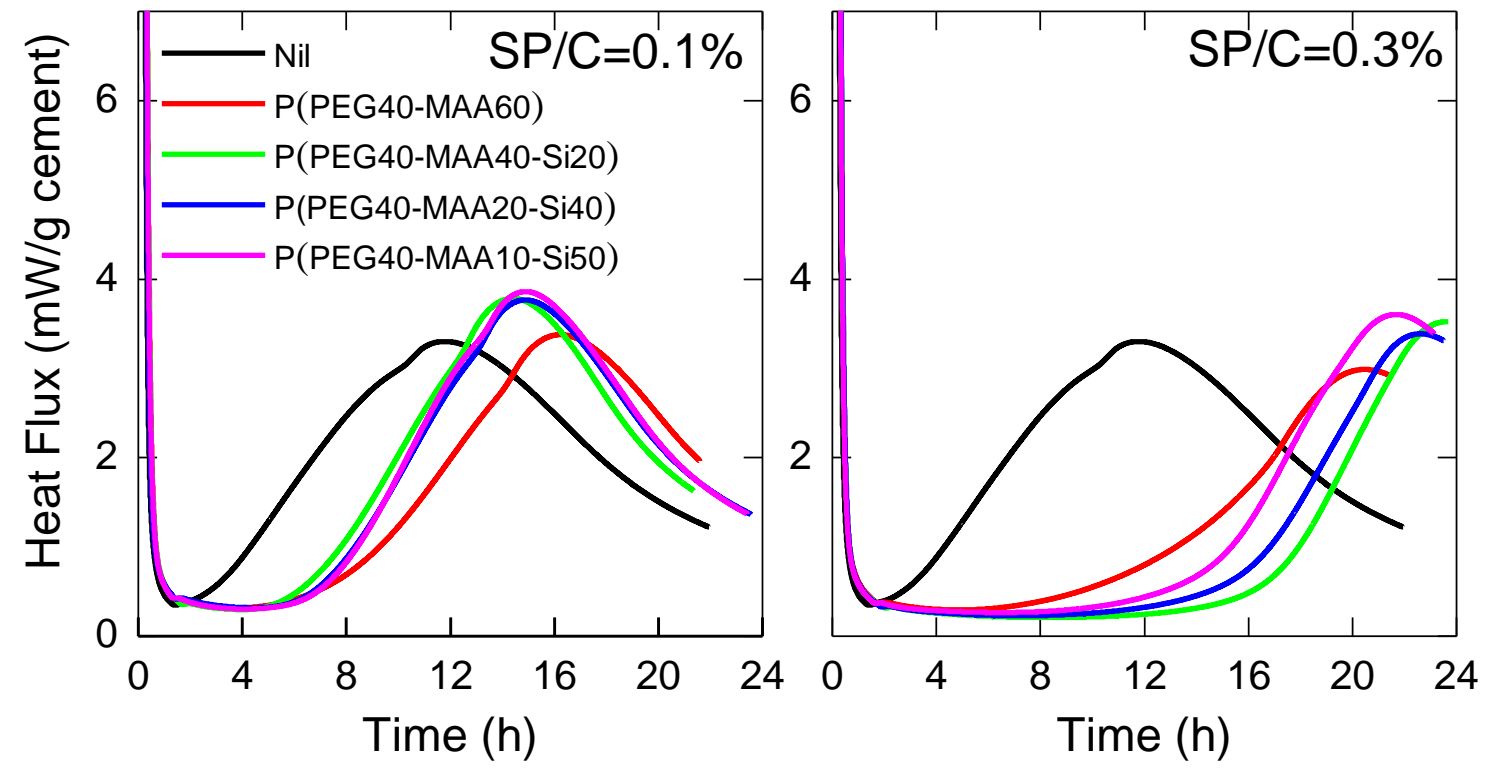

Fig. 7. Calorimetric curves of "Bussac" cement setting at $\mathrm{W} / \mathrm{C}=0.44$ formulated with $0.1 \%$ and $0.3 \%$ in mass of superplasticizers. 


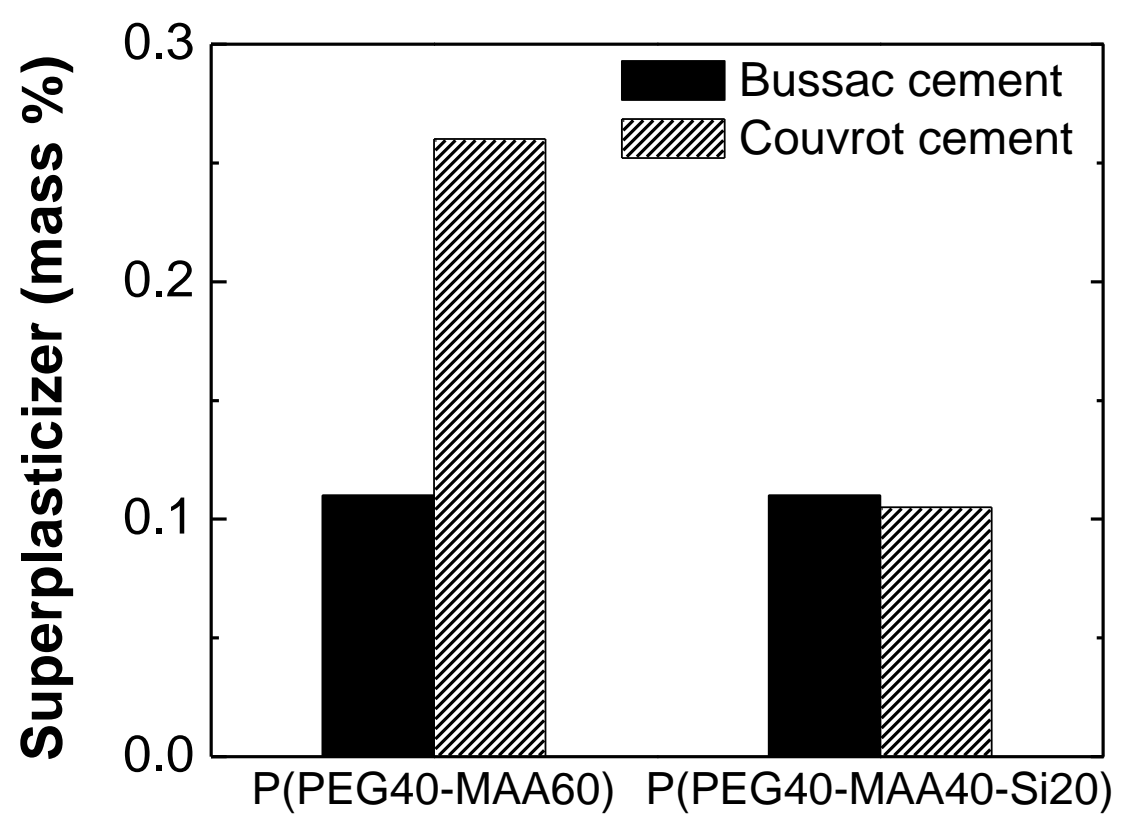

Fig. 8. Percentage of SPs (relative to cement) required in mortar formulated with a low (Bussac) and a high (Couvrot) sulfate alkali cement to achieve a constant slump of $210 \pm 10$ $\mathrm{mm}$. 